\title{
Generalized optimizations of two-stage forging of micro/meso copper fastener
}

\author{
Shih-Hsien Lin ${ }^{1}$, Un-Chin Chai, Gow-Yi Tzou ${ }^{2, *}$, and Dyi-Cheng Chen ${ }^{1}$ \\ ${ }^{1}$ Department of Industrial Education and Technology, National Changhua University of Education, \\ Changhua, 500, Taiwan \\ ${ }^{2}$ Department of Mechanical and Automation Engineering, Chung-Chou University of Science and \\ Technology, Yuanlin, Changhua, 510, Taiwan
}

\begin{abstract}
Three are generalized simulation optimizations considering the forging force, the die stress, and the dual-goals in two-stage forging of micro/meso copper fastener. Constant shear friction between the dies and workpiece is assumed to perform multi-stage cold forging forming simulation analysis, and the Taguchi method with the finite element simulation has been used for mold-and-dies parameters design simulation optimizations considering the forging force, die stress, and dual-goals. The die stress optimization is used to explore the effects on effective stress, effective strain, velocity field, die stress, forging force, and shape of product. The influence rank to forging process of micro/meso copper fastener for three optimizations can be determined, and the optimal parameters assembly consider die stress can be obtained in this study. It is noted that the punch design innovation can reduce the forging force and die stress.
\end{abstract}

\section{Introduction}

Shah et al. [1] used FEM to do cold forging simulation analysis of thread head, besides comparing simulation results with experiment to verify the acceptance of this model. Vickers et al. [2] used plasticine, aluminum, 6061-T6 aluminum alloy as the simulated materials, using the experimental to analyze cold forging of thread head. MacCormack et al. [3] used FEM simulation to analyze the die of hexagonal bolt in the multi-stage cold forging, to increase die's life and successfully reduce die stress $17.7 \%$. Asnafi [4] used FEM to analyze the dies of cold forging, the reasons for failure of dies can be found through the experimental method. Sun et al. [5] aimed at stainless automotive battery fastener to do the processing animation simulation and FEM analysis of multi-stage cold forging; propose the pass schedule plan to carry out the experiments comparing with FEM simulation results the good agreement has been done. Shih et al. [6] proposed FEM simulation and experimental verification on multi-stage forming of flange sleeve; using Deform 3D commercial software to design the pass schedule and the dies dimensions, and realistic experiments have been performed to verify the acceptance of FEM simulation.

*Corresponding author: gowyitzou@gm.ccut.edu.tw 
Engel et al. [7] firstly used basic research to realize what is micro-forming. Wang et al. [8] explore size effects of the cavity dimension on the micro-forming ability during coining process. Gau et al. [9] utilized an experimental study to investigate into the size effects on flow stress and formability of aluminum and brass for micro-forming; the size effect reduces the flow stress. Engel et al. [10] continued to explore tribology in micro-forming; the tribology concept for micro-forming is different from traditional tribology. Chen [11] proposed the robust design on equal channel angle extrusion of Ti-6Al-4V using Taguchi method; combine FEM simulation with Taguchi method to obtain the optimal parameters assembly to reach robust design. G.Y. Tzou et al.[12] first proposed a study to change the traditional punch design of micro/meso copper fastener forging, and to conduct the forging force optimization to explore the effects on effective stress, effective strain, velocity field, die stress, and shape of product. The optimal parameters assembly and the control factors influence could be obtained. This present research then proposes three generalized optimizations and comparisons including the forging force, die stress, and dual-goals.

\section{FEM analyses}

\subsection{Material properties and product specifications}

Figure 1 is a diagram of micro/meso copper fastener for each pass. The copper fastener in the second stage is the specification of final product. The workpiece is a copper, C2600; the flow stress is $\sigma=553.547 \varepsilon^{0.26}$, which is an elastic-plastic material. This study uses Deform-2D to perform FEM simulation; the simulation conditions are summarized in table 1. The friction is assumed to be constant shear friction. Figure 2 shows schematic diagram before and after forming for the first pass. Figure 3 shows a schematic diagram of punch and die for the first pass. In Figure 3, the major four parameters are shown as, punch angle $(\alpha)$, die angle $(\beta)$, die bottom height $(\mathrm{H})$, and die filet $(\mathrm{R})$; Taguchi method can be used to carry out the force optimization with these four control factors. The orthogonal table, $\mathrm{L}_{9}\left(3^{4}\right)$, can be used to do experimental plan including four control factors and three levels. The signal noise ratio can be used to obtain the optimal parameters assembly of reducing forging force.

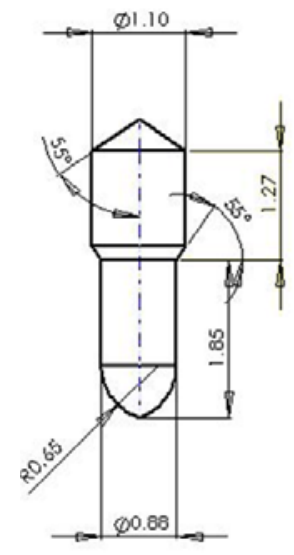

Pass 1

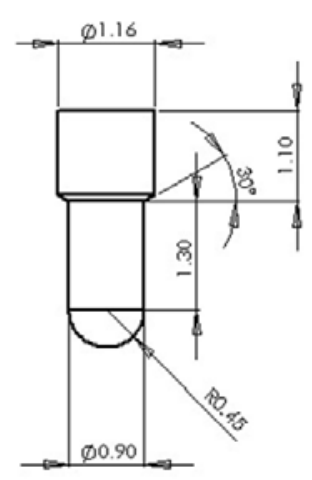

Pass 2

Fig. 1. Diagram of micro/meso copper fastener for each pass. 


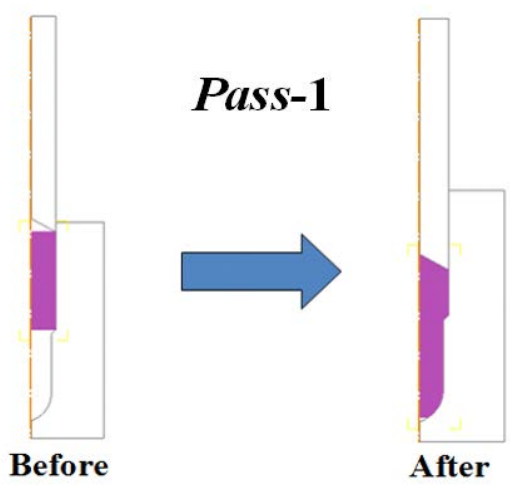

Fig. 2. Schematic diagram before and after forming for the first pass.

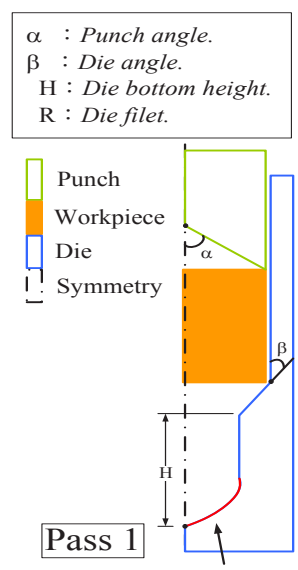

Fig. 3. Schematic diagram of punch and diefor the first pass.

Table 1. FEM simulation conditions.

\begin{tabular}{|c|c|}
\hline Workpiece & C2600 \\
\hline Young's Modulus $(E)$ & $110 \mathrm{GPa}$ \\
\hline Poisson's Ratio $(v)$ & 0.28 \\
\hline Power law & $\sigma=553.547 \varepsilon^{0.26}$ \\
\hline Object type & Elasto-Plastic \\
\hline Number of Elements & 8800 \\
\hline Front die & Rigid body \\
\hline Velocity $\left(V_{o}\right)$ & $0.1 \mathrm{~mm} / \mathrm{s}$ \\
\hline Shear Friction $(m)$ & 0.2 \\
\hline Rear die & Rigid body \\
\hline Velocity $\left(V_{o}\right)$ & $0 \mathrm{~mm} / \mathrm{s}$ \\
\hline Shear Friction $(m)$ & 0.2 \\
\hline
\end{tabular}




\section{Optimization and results}

\subsection{Optimization of forging force}

The first part is doing the optimization of forging force shown in Figure 4. Figure 4 shows control factors and levels for forging force optimization.

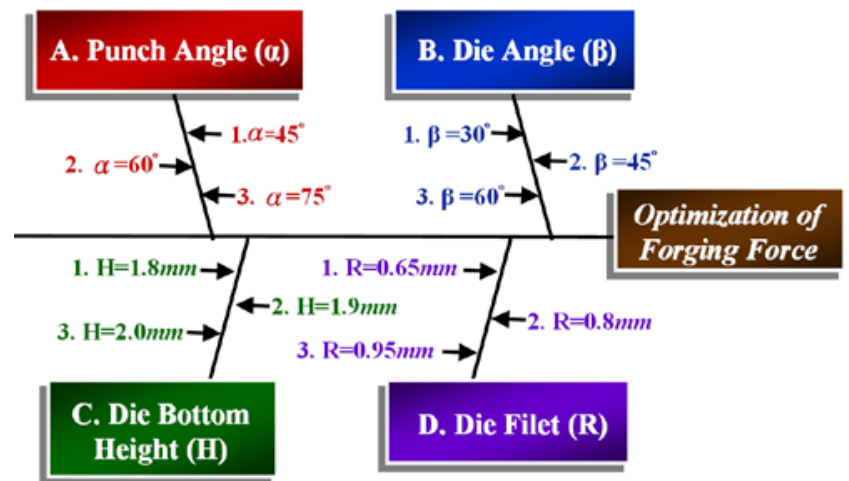

Fig. 4. Control factors and levels for forging force optimization.

According to the layout in Figure 4, $\mathrm{L}_{9}\left(3^{4}\right)$ can be used to obtain $\mathrm{S} / \mathrm{N}$ of forging force, the analysis results are summarized in Table 2 . In Table 2, the fourth simulation experiment (IV) has the maximum forging force and the minimum $\mathrm{S} / \mathrm{N}$; the ninth simulation experiment (IX) has the minimum forging force and the maximum $\mathrm{S} / \mathrm{N}$, where the best parameters assembly in orthogonal table is $\mathrm{A}_{3} \mathrm{~B}_{3} \mathrm{C}_{2} \mathrm{D}_{1}$ (i.e. $\alpha=75^{\circ}, \beta=60^{\circ}, \mathrm{H}=1.9 \mathrm{~mm}$, $\mathrm{R}=0.65 \mathrm{~mm}$ ). Table 3 shows $\mathrm{S} / \mathrm{N}$ response characteristics, form this table, the punch angle $(\alpha)$ influences to forging force very much, then next is die angle $(\beta)$. The optimal parameters assembly is $\mathrm{A}_{1} \mathrm{~B}_{3} \mathrm{C}_{2} \mathrm{D}_{1}$ (i.e. $\alpha=45^{\circ}, \beta=60^{\circ}, \mathrm{H}=1.9 \mathrm{~mm}, \mathrm{R}=0.65 \mathrm{~mm}$ ). Using this assembly to run Deform-2D, the forging force is $1.53 \mathrm{kN}$. The optimal force, $1.53 \mathrm{kN}$, is lower than that obtained from the orthogonal table, $1.72 \mathrm{kN}$. Let this optimal force compare to the worst force in Table $\mathrm{L}_{9}\left(3^{4}\right)$, the forging force is improved $47.67 \%$. If let this optimal force compare to the best force in Table $2, \mathrm{~L}_{9}\left(3^{4}\right)$, the forging force is improved $12.4 \%$.

Table 2. $\mathrm{L}_{9}\left(3^{4}\right)$ simulation results for forging force.

\begin{tabular}{|c|c|c|c|c|c|c|}
\hline EXP & $\begin{array}{c}\mathrm{A} \\
(\alpha)\end{array}$ & $\begin{array}{c}\mathrm{B} \\
(\beta)\end{array}$ & $\begin{array}{c}\mathrm{C} \\
(\mathrm{H})\end{array}$ & $\begin{array}{c}\mathrm{D} \\
(\mathrm{R})\end{array}$ & Force $(\mathrm{kN})$ & $\mathrm{S} / \mathrm{N}$ \\
\hline I & 1 & 1 & 1 & 1 & 2.05 & -6.235 \\
\hline II & 1 & 2 & 2 & 2 & 1.90 & -5.575 \\
\hline III & 1 & 3 & 3 & 3 & 1.90 & -5.575 \\
\hline IV & $\underline{\mathbf{2}}$ & $\underline{\mathbf{1}}$ & $\underline{\mathbf{2}}$ & $\underline{\mathbf{3}}$ & $\underline{\mathbf{2 . 5 4}}$ & $\underline{\mathbf{- 8 . 0 9 7}}$ \\
\hline V & 2 & 2 & 3 & 1 & 2.20 & -6.848 \\
\hline VI & 2 & 3 & 1 & 2 & 2.29 & -7.197 \\
\hline VII & 3 & 1 & 3 & 2 & 2.32 & -7.310 \\
\hline VIII & 3 & 2 & 1 & 3 & 1.88 & -5.483 \\
\hline IX & $\mathbf{3}$ & $\mathbf{3}$ & $\mathbf{2}$ & $\mathbf{1}$ & $\mathbf{1 . 7 2}$ & $\mathbf{- 4 . 7 1 1}$ \\
\hline
\end{tabular}


Table 3. S/N response characteristics for forging force.

\begin{tabular}{|c|c|c|c|c|}
\hline $\mathrm{S} / \mathrm{N}$ & $\mathrm{A}(\alpha)$ & $\mathrm{B}(\beta)$ & $\mathrm{C}(H)$ & $\mathrm{D}(R)$ \\
\hline Level 1 & $\mathbf{- 5 . 7 9 5 1}$ & -7.2138 & -6.3050 & $\mathbf{- 5 . 9 3 1 4}$ \\
\hline Level 2 & -7.3806 & -5.9689 & $\mathbf{- 6 . 1 2 7 4}$ & -6.6938 \\
\hline Level 3 & -5.8345 & $\mathbf{- 5 . 8 2 7 5}$ & -6.5778 & -6.3850 \\
\hline Effect & 1.5855 & 1.3864 & 0.4503 & 0.7625 \\
\hline Rank & 1 & 2 & 4 & 3 \\
\hline
\end{tabular}

\subsection{Optimization of die stress}

The second part is doing the optimization of die stress shown in Figure 5. Figure 5 shows control factors and levels for die stress optimization.

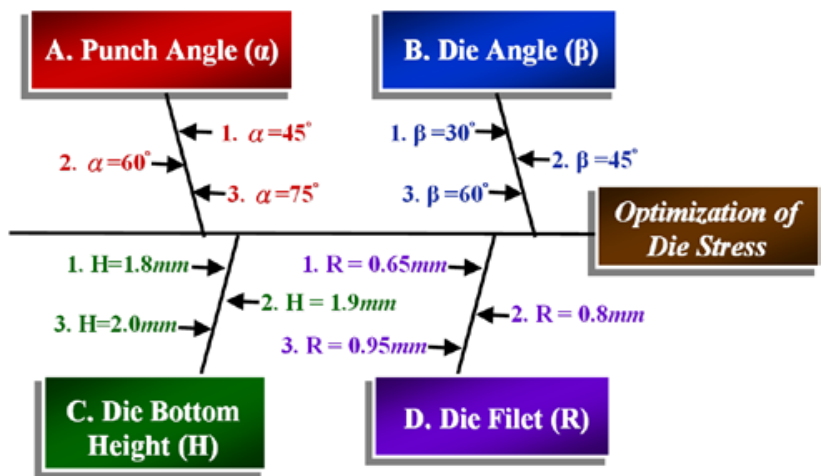

Fig. 5. Control factors and levels for die stress optimization.

Table 4. $\mathrm{L}_{9}\left(3^{4}\right)$ simulation results for die stress.

\begin{tabular}{|c|c|c|c|c|c|c|}
\hline EXP & $\begin{array}{c}\mathrm{A} \\
(\alpha)\end{array}$ & $\begin{array}{c}\mathrm{B} \\
(\beta)\end{array}$ & $\begin{array}{c}\mathrm{C} \\
(\mathrm{H})\end{array}$ & $\begin{array}{c}\mathrm{D} \\
(\mathrm{R})\end{array}$ & $\begin{array}{c}\text { Stress } \\
(\mathrm{MPa})\end{array}$ & $\mathrm{S} / \mathrm{N}$ \\
\hline I & 1 & 1 & 1 & 1 & 3480 & -70.832 \\
\hline II & $\underline{\mathbf{1}}$ & $\underline{\mathbf{2}}$ & $\underline{\mathbf{2}}$ & $\underline{\mathbf{2}}$ & $\underline{\mathbf{3 5 7 0}}$ & $\underline{\mathbf{- 7 1 . 0 5 3}}$ \\
\hline III & 1 & 3 & 3 & 3 & 3550 & -71.005 \\
\hline IV & 2 & 1 & 2 & 3 & 3430 & -70.706 \\
\hline V & $\mathbf{2}$ & $\mathbf{2}$ & $\mathbf{3}$ & $\mathbf{1}$ & $\mathbf{3 2 4 0}$ & $-\mathbf{7 0 . 2 1 1}$ \\
\hline VI & 2 & 3 & 1 & 2 & 3370 & -70.553 \\
\hline VII & 3 & 1 & 3 & 2 & 3290 & -70.344 \\
\hline VIII & 3 & 2 & 1 & 3 & 3510 & -70.906 \\
\hline IX & 3 & 3 & 2 & 1 & 3390 & -70.604 \\
\hline
\end{tabular}

According to the layout in Figure 5, $\mathrm{L}_{9}\left(3^{4}\right)$ can be used to obtain $\mathrm{S} / \mathrm{N}$ of die stress, the analysis results are summarized in Table 4. In Table 4, the second simulation experiment (II) has the maximum die stress and the minimum $\mathrm{S} / \mathrm{N}$; the fifth simulation experiment $(\mathrm{V})$ has the minimum die stress and the maximum $\mathrm{S} / \mathrm{N}$, where the best parameters assembly in orthogonal table is $\mathrm{A}_{2} \mathrm{~B}_{2} \mathrm{C}_{3} \mathrm{D}_{1}$ (i.e. $\alpha=60^{\circ}, \beta=45^{\circ}, \mathrm{H}=2.0 \mathrm{~mm}, \mathrm{R}=0.65 \mathrm{~mm}$ ). Table 5 shows 
$\mathrm{S} / \mathrm{N}$ response characteristics, form this table, the punch angle $(\alpha)$ influences to die stress very much, then next is die filet (R). The optimal parameters assembly is $A_{2} B_{1} C_{3} D_{1}$ (i.e. $\left.\alpha=60^{\circ}, \beta=60^{\circ}, H=2.0 \mathrm{~mm}, \mathrm{R}=0.65 \mathrm{~mm}\right)$. Using this assembly to run Deform- $2 \mathrm{D}$, the die stress is $2500 \mathrm{MPa}$. The optimal dies stress, $2500 \mathrm{MPa}$, is lower than that obtained from the orthogonal table, $3240 \mathrm{MPa}$. Let this optimal die stress compare to the worst force in Table $\mathrm{L}_{9}\left(3^{4}\right)$, the die stress is improved $42.8 \%$. If let this optimal force compare to the best force in Table 5, and the die stress is improved 29.6\%.

Table 5. S/N response characteristics for die stress.

\begin{tabular}{|c|c|c|c|c|}
\hline $\mathrm{S} / \mathrm{N}$ & $\mathrm{A}(\alpha)$ & $\mathrm{B}(\beta)$ & $\mathrm{C}(\mathrm{H})$ & $\mathrm{D}(\mathrm{R})$ \\
\hline Level 1 & -70.9632 & $-\mathbf{7 0 . 6 2 7 1}$ & -70.7634 & $-\mathbf{7 0 . 5 4 8 8}$ \\
\hline Level 2 & $-\mathbf{7 0 . 4 8 9 8}$ & -70.7235 & -70.7877 & -70.6500 \\
\hline Level 3 & -70.6180 & -70.7204 & $-\mathbf{7 0 . 5 1 9 8}$ & -70.8722 \\
\hline Effect & 0.4734 & 0.0963 & 0.2680 & 0.3234 \\
\hline Rank & 1 & 4 & 3 & 2 \\
\hline
\end{tabular}

\subsection{Optimization of dual-goals}

In this study, the minimization of die stress is set as the primary goal and the minimization of forging force is set as the secondary goal. The optimum combination of parameters is shown in Table 6 . Table 6 shows the comparison of the optimum combinations of parameters and the influence ranks of forging parameters between the die stress optimization and forging force optimization. As shown in Table 6, the optimum combination of parameters for the die stress optimization is $\mathrm{A}_{2} \mathrm{~B}_{1} \mathrm{C}_{3} \mathrm{D}_{1}\left(\alpha=60^{\circ}, \beta=30^{\circ}\right.$, $\mathrm{H}=2.0 \mathrm{~mm}, \mathrm{R}=0.65 \mathrm{~mm})$. Punch angle $(\alpha)$ has the most effect on the die stress, following by die filet $(\mathrm{R})$, die bottom height $(\mathrm{H})$, and the die angle $(\beta)$. In the forging force optimization, the optimum combination of parameters is $\mathrm{A}_{2} \mathrm{~B}_{3} \mathrm{C}_{2} \mathrm{D}_{1}\left(\alpha=60^{\circ}, \beta=30^{\circ}, \mathrm{H}=1.9 \mathrm{~mm}\right.$, $\mathrm{R}=0.65 \mathrm{~mm})$. Punch angle $(\alpha)$ has the largest influence on the forging force, following by die angle $(\beta)$, die fillet $(\mathrm{R})$, and the die bottom height $(\mathrm{H})$.

As mentioned before, the minimization of die stress is the primary goal in this part and the minimization of forging force is the secondary goal. Therefore, the first two forging parameters of the die stress optimization are chosen first. They are punch angle (A2) and die filet (D1). Then, the first two forging parameters of the die stress optimization are chosen. However, the first (A2) and the fourth (D1) forging parameters of the forging force optimization overlap with the forging parameters of the die stress optimization (A2 and D1). Therefore, the second (B3) and the third (C2) forging parameters of the forging force optimization are chosen. The optimum combination of parameters for the dual-goals optimization is formed as $\mathrm{A}_{2} \mathrm{~B}_{3} \mathrm{C}_{2} \mathrm{D}_{1}\left(\alpha=60^{\circ}, \beta=60^{\circ}, \mathrm{H}=1.9 \mathrm{~mm}, \mathrm{R}=0.65 \mathrm{~mm}\right)$.

Table 6. $\mathrm{S} / \mathrm{N}$ response characteristics for the dual-goals optimization.

\begin{tabular}{|c|c|c|c|c|c|}
\hline \multirow{2}{*}{$\begin{array}{c}\text { Primary goal: } \\
\text { Die stress }\end{array}$} & $\begin{array}{c}\text { Optimum combination of } \\
\text { parameters }\end{array}$ & $\mathrm{A}_{2}(\alpha)$ & $\mathrm{B}_{1}(\beta)$ & $\mathrm{C}_{3}(\mathrm{H})$ & $\mathrm{D}_{1}(\mathrm{R})$ \\
\cline { 2 - 7 } & Influence rank & 1 & 4 & 3 & 2 \\
\hline $\begin{array}{c}\text { Secondary goal: } \\
\text { Forging force }\end{array}$ & $\begin{array}{c}\text { Optimum combination of } \\
\text { parameters }\end{array}$ & $\mathrm{A}_{1}(\alpha)$ & $\mathrm{B}_{3}(\beta)$ & $\mathrm{C}_{2}(\mathrm{H})$ & $\mathrm{D}_{1}(\mathrm{R})$ \\
\cline { 2 - 7 } & Influence rank & 1 & 2 & 4 & 3 \\
\hline
\end{tabular}




\subsection{Analysis of generalized optimization}

The optimum combinations of parameters of three generalized optimizations are summarized as follows:

Optimum combination of parameters for dual-goals : $\mathrm{A}_{2} \mathrm{~B}_{3} \mathrm{C}_{2} \mathrm{D}_{1}$, i.e. $\alpha=60^{\circ}, \beta=60^{\circ}, \mathrm{H}=1.9$ $\mathrm{mm}, \mathrm{R}=0.65 \mathrm{~mm}$.

Optimum combination of parameters for die stress : $A_{2} B_{1} C_{3} D_{1}$, i.e. $\alpha=60^{\circ}, \beta=30^{\circ}, H=2 \mathrm{~mm}$, $\mathrm{R}=0.65 \mathrm{~mm}$.

Optimum combination of parameters for forging force : $A_{1} B_{3} C_{2} D_{1}$, i.e. $\alpha=45^{\circ}, \beta=60^{\circ}$, $\mathrm{H}=1.9 \mathrm{~mm}, \mathrm{R}=0.65 \mathrm{~mm}$.
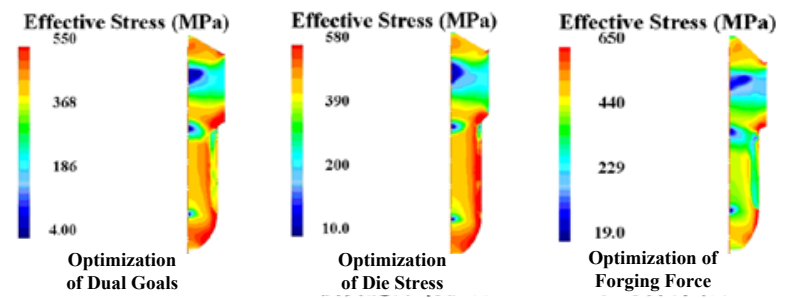

Fig. 6. Effective stresses for three generalized optimization at pass 1.

Figure 6 is effective stresses for three generalized optimization at pass 1 . The maximun effective stress is $550 \mathrm{MPa}$ for dual-goals optimization, $580 \mathrm{MPa}$ for dies stress optimization, and $650 \mathrm{MPa}$ for forging force optimization. The smaller effective stress is induced in the dual-goals optimization.

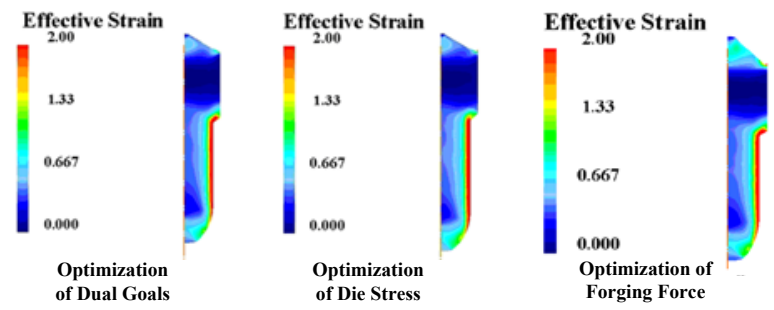

Fig. 7. Effective strains for three generalized optimization at pass 1.

Figure 7 is effective strains for three generalized optimization at pass 1 . The maximun effective strain is $2 \mathrm{~mm} / \mathrm{mm}$ for generalized optimization at pass 1 .
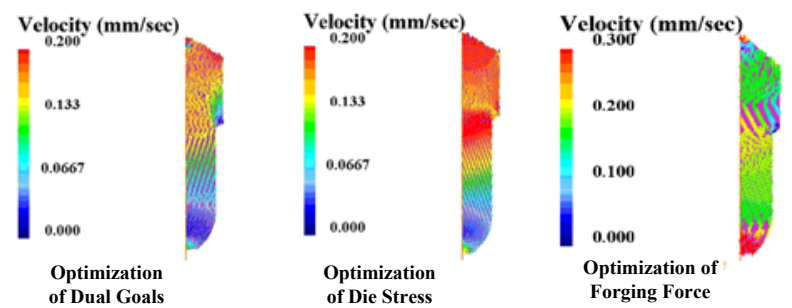

Fig. 8. Velocity fields for three generalized optimization at pass 1.

Figure 8 is velocity fields for three generalized optimization at pass 1 . The maximun velocity is $0.3 \mathrm{~mm} / \mathrm{sec}$ for forging force optimization at pass 1 . 

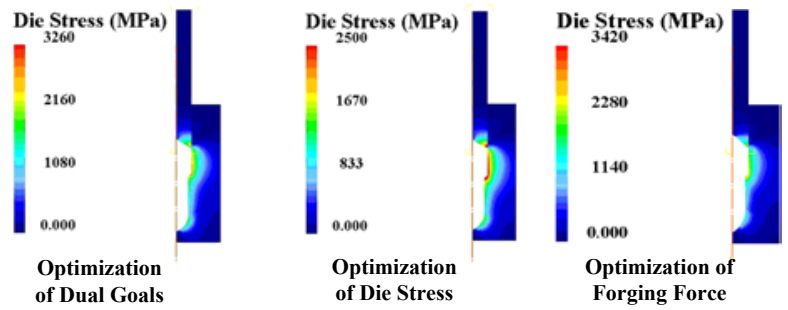

Fig. 9. Die stresses for three generalized optimization at pass 1.

Figure 9 is dies stresses for three generalized optimization at pass 1 . The maximun die stress is $3420 \mathrm{MPa}$ for forging force optimization, $3260 \mathrm{MPa}$ for dual-goals optimization, and $2500 \mathrm{MPa}$ for die stress optimization .

The forging parts in the first pass can be transferred to the second pass to form the final product shown in Figure 10.

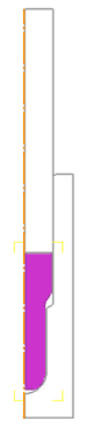

Before

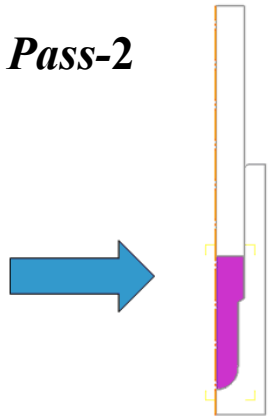

After

Fig. 10. Schematic diagram before and after forming for the second pass.
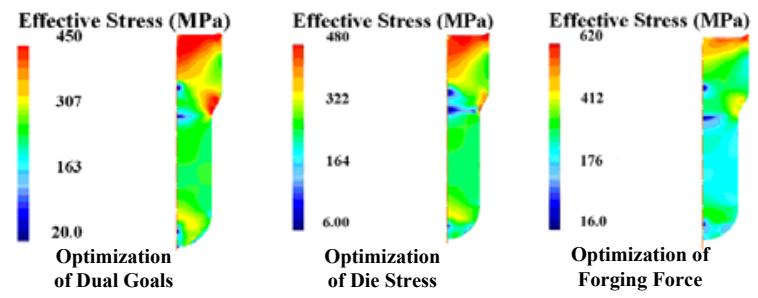

Fig. 11. Effective stresses for three generalized optimization at pass 2 .

Figure 11 is effective stresses for three generalized optimization at pass 2. The maximun effective stress is $450 \mathrm{MPa}$ for dual-goals optimization, $480 \mathrm{MPa}$ for dies stress optimization, and $620 \mathrm{MPa}$ for forging force optimization. The smaller effective stress is induced in the dual-goals optimization. 

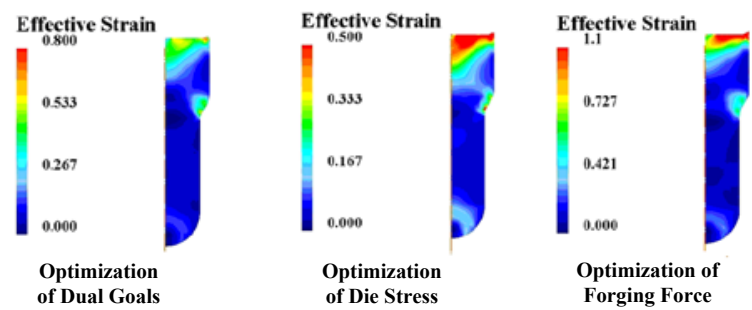

Fig. 12. Effective strains for three generalized optimization at pass 2 .

Figure 12 is effective strains for three generalized optimization at pass 2 . The maximun effective strain is $0.8 \mathrm{~mm} / \mathrm{mm}$ for dual-goals optimization, $0.55 \mathrm{~mm} / \mathrm{mm}$ for dies stress optimization, and $1.1 \mathrm{~mm} / \mathrm{mm}$ for forging force optimization. The smaller effective strain is induced in the die stress optimization.
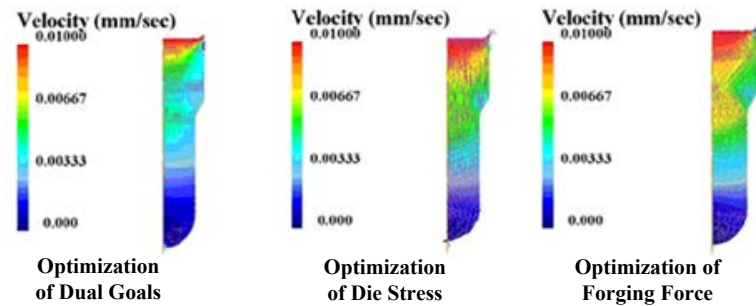

Fig. 13. Velocity fields for three generalized optimization at pass 2 .

Figure 13 is velocity fields for three generalized optimization at pass 2 . The maximun velocity is $0.1 \mathrm{~mm} / \mathrm{sec}$ for forging force optimization at pass 2 .
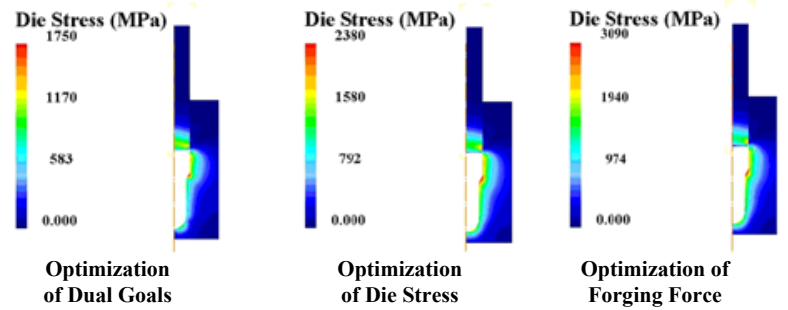

Fig. 14. Die stresses for three generalized optimization at pass 2.

Figure 14 is dies stresses for three generalized optimization at pass 2 . The maximun die stress is $1750 \mathrm{MPa}$ for dual-goals optimization, 2380MPa for die stress optimization, and 3090MPa for forging force optimization .

\section{Conclusions}

This study proposes the three generalized optimizations combining FEM simulations and Taguchi method to obtain the optimal parameters assembly, the effective stress, the effective strain, the velocity field, and the die stress. Moreover the influence rank to the forging process can be determined for three generalized optimizations in this study. The optimum combinations of parameters of three generalized optimizations are summarized as follows: 
1. Optimum combination of parameters for dual-goals : $\mathrm{A}_{2} \mathrm{~B}_{3} \mathrm{C}_{2} \mathrm{D}_{1}$, i.e. $\alpha=60^{\circ}, \beta=60^{\circ}$, $\mathrm{H}=1.9 \mathrm{~mm}, \mathrm{R}=0.65 \mathrm{~mm}$. The influence rank to the dual-goals is punch angle $>$ die filet $>$ die angle $>$ die bottom height.

2. Optimum combination of parameters for die stress : $\mathrm{A}_{2} \mathrm{~B}_{1} \mathrm{C}_{3} \mathrm{D}_{1}$, i.e. $\alpha=60^{\circ}, \beta=30^{\circ}$, $\mathrm{H}=2 \mathrm{~mm}, \mathrm{R}=0.65 \mathrm{~mm}$. The influence rank to the die stress is punch angle $>$ die filet $>$ die bottom height $>$ die angle.

3. Optimum combination of parameters for forging force : $\mathrm{A}_{1} \mathrm{~B}_{3} \mathrm{C}_{2} \mathrm{D}_{1}$, i.e. $\alpha=45^{\circ}, \beta=60^{\circ}$, $\mathrm{H}=1.9 \mathrm{~mm}, \mathrm{R}=0.65 \mathrm{~mm}$. The influence rank to the forging force is punch angle $>$ die angle $>$ die filet $>$ die bottom height.

4. At the die angle location, the maximum effective stress, the maximum effective strain, and the die stress are occurred. Especially for the die stress, the die stress is still under the allowable stress of WC mold.

5. The dimensions simulated can compare with the specifications, the error is under $2 \%$ shown in Fioure 14 It indicates the FFM simulations can be accepted.

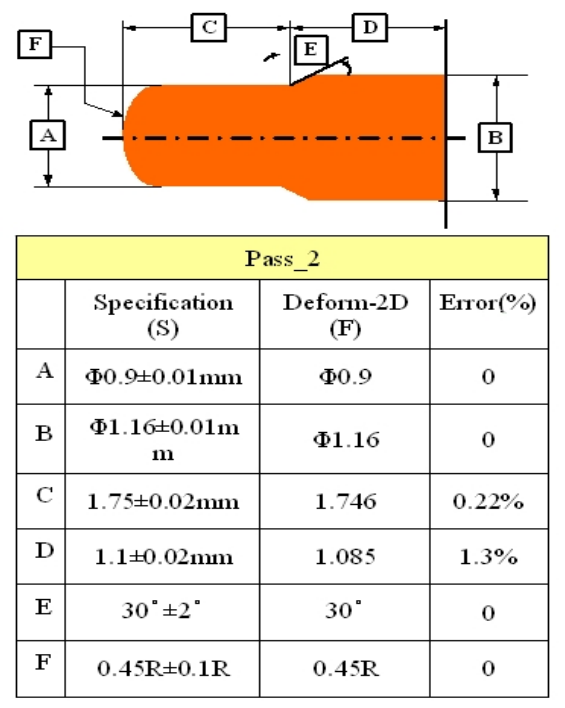

Fig. 15 . Diensions comparisons of simulations and specifications.

\section{Acknowledgments}

Thanks for the project's supports of Ministry of Economic Affairs (MOEA), and Ministry of Education (MOE) to complete this research and the financial supports.

\section{References}

1. S. N. Shah, S. Kobayashi, Rigid-plastic analysis in cold heading by the matrix method, Proc. 15th International Conference on Machine Tool Design Research, 603-608 (1974)

2. G.W. Vickers, A. Plumtree, R. Sowerby, J.L. Duncan, Simulation of the heading process, J. Engineering Materials and Technology, 126-135 (1975) 
3. C. MacCormack, J. Monaghan, A finite element analysis of cold-forging dies using two-and three-dimensional models, J. of Materials Processing Technology, 118, 286292 (2001)

4. N. Asnafi, On tool stresses in cold heading of fasteners, Engineering Failure Analysis. 6, 321-335 (1999)

5. M.C. Sun, G.Y Tzou., L.A. Zheng, Processing animation simulation and FEM analysis of multi-stage cold forging of stainless automotive battery fastener, Indian Journal of Engineering \& Materials Sciences, 20, 219-224 (2013).

6. C.W. Shih, G.Y. Tzou, K.H. Chang, FEM simulation and experimental verification on multi-stage forming of flange sleeve, Journal of Chinese Society Mechanical Engineers, 35, 243-250 (2014)

7. U. Engel and R. Eckstein, Microforming-from basic research to its realization, J. of Materials Processing Technology, 125-126, 35-44 (2002)

8. C.J. Wang, D.B. Shan, J. Zhou, B. Guo, L.N. Sun, Size effects of the cavity dimension on the microforming ability during coining process, J. of Materials Processing Technology, 187-188, 256-259 (2007)

9. J. T. Gau, C. Ptincipe, J. Wang, An experimental study on size effects on flow stress and formability of aluminum and brass for microforming, Journal of Materials Processing Technology, 184, 42-46 (2007)

10. U. Engel, Tribology in micro forming, Wear, 260, 265-273 (2006)

11. D.C. Chen, G.Y. Tzou, Y.J. Li, Robust design on equal channel angle extrusion of Ti6Al-4V using Taguchi method, International Journal of Material Science, 5, 1 (2015), doi:10.12783/ijmsci.2015.0501

12.G.Y. Tzou, U.C. Chai, S.H. Lin, D.C. Chen, Optimal parameters design and analysis of multi-stage forging of a micro/meso copper fastener, Advances in Energy Science and Equipment Engineering, II, 1307-1310 (2016) 